\title{
Mapeamento das Ações Realizadas pelos Projetos Parceiros do Programa Meninas Digitais na Região Sul
}

\author{
Aline Vieira de Mello, Alice Fonseca Finger, Letícia Gindri, Amanda Meincke Melo \\ Universidade Federal do Pampa (Unipampa) - Campus Alegrete \\ Av. Tiarajú, 810 -Ibirapuitã-97.546-550-Alegrete -RS -Brasil \\ \{alinemello, alicefinger, leticiagindri, amandamelo\}@unipampa.edu.br
}

\begin{abstract}
The Meninas Digitais Program has 116 active partner projects, 23 of which are or have been developed in the southern region of Brazil. This article presents and discusses the results of exploratory and descriptive research, with a qualitative approach, which aims at knowing and publicizing actions carried out by partner projects of the program developed in this region. Thus, it is expected to show its alignment with the objectives of the Meninas Digitais Program, approximations and differences in terms of themes and strategies, as well as to encourage cooperation between the projects.
\end{abstract}

Resumo. O Programa Meninas Digitais possui 116 projetos parceiros ativos, sendo que 23 são ou foram desenvolvidos na região Sul do Brasil. Este artigo apresenta e discute resultados de uma pesquisa exploratória e descritiva, de abordagem qualitativa, que tem como objetivo conhecer e divulgar as ações executadas por projetos parceiros do programa desenvolvidos nessa região. Com isso, espera-se evidenciar seu alinhamento com os objetivos do Programa Meninas Digitais, aproximações e diferenças em termos de temas e estratégias, assim como incentivar a cooperação entre os projetos.

\section{Introdução}

É objetivo do Programa Meninas Digitais, da Sociedade Brasileira de Computação (SBC):

[...] divulgar a área da Computação e suas tecnologias para despertar o interesse de meninas estudantes do ensino médio (nas suas diversas modalidades) e dos anos finais do ensino fundamental, para que estas conheçam melhor a área e sintam-se motivadas em seguir uma carreira em Computação. [SBC 2021]

O programa teve início em 2011 [Maciel e Bim 2016] e atualmente possui 116 projetos parceiros ativos, nas diferentes regiões do país, sendo que 23 projetos são ou foram desenvolvidos na região Sul. Embora a página do Meninas Digitais [SBC 2021] traga informações sobre esses projetos (ex.: título, descrição, status, início, contatos), estas são bastante gerais, sem detalhamento das ações desenvolvidas ao longo do tempo.

No Women in Information Technology (WIT), evento promovido anualmente pela Sociedade Brasileira de Computação (SBC), Nunes et al. (2016a) apresentaram um mapeamento sistemático de iniciativas brasileiras que incentivam a entrada de mulheres na Computação. No ano de 2014, as autoras identificaram 16 projetos, sendo o mais antigo criado no ano de 2005. As autoras também apresentam um mapeamento sistemático de iniciativas em língua inglesa [Nunes et al. 2016b], no qual identificaram 
59, sendo a mais antiga de 1978. Em ambos os casos [Nunes et al. 2016a][Nunes et al. 2016b], além de serem identificadas a quantidade de iniciativas e seu ano de criação, estas foram classificadas em categorias (ex.: Workshop, Palestras, Fórum de discussão etc.). No caso das iniciativas estrangeiras [Nunes et al. 2016b], procurou-se também identificar o seu alcance, sendo a maioria com foco nos Estados Unidos da América (EUA).

Frigo et al. (2020) apresentaram um relato das principais ações desenvolvidas no projeto Meninas Digitais - Regional Sul - da Universidade Federal de Santa Catarina (UFSC), o qual é parceiro do Programa Meninas Digitais desde 2012, com o intuito de inspirar novos projetos parceiros. As autoras mencionam que diversos outros projetos têm divulgado suas ações no Women in Information Technology (WIT), do Congresso da Sociedade Brasileira de Computação. Por fim, relatam as oficinas desenvolvidas com diferentes temáticas, além de fóruns, palestras e uso de redes sociais como forma de publicar as ações desenvolvidas pelo projeto.

Diferentemente dos trabalhos mencionados [Nunes et al. 2016a][Nunes et al. 2016b][Frigo et al. 2020], este artigo apresenta e discute resultados de uma pesquisa exploratória e descritiva, de abordagem qualitativa, que tem como objetivo conhecer e divulgar as ações desenvolvidas por projetos parceiros do Programa Meninas Digitais sediados na região Sul do Brasil, evidenciando seu alinhamento com os objetivos do Programa Meninas Digitais, aproximações e diferenças quanto aos temas e estratégias, assim como incentivar a cooperação entre os projetos. O texto está organizado como segue: a seção 2 aborda a metodologia adotada para a realização dessa pesquisa; os resultados são descritos e discutidos na seção 3; e, por fim, são apresentadas as considerações finais na seção 4 .

\section{Metodologia}

Esta é uma pesquisa exploratória e descritiva que adota abordagem qualitativa, em que as pesquisadoras se propõem a compreender e interpretar as informações obtidas. Quanto ao procedimento, um survey foi conduzido usando uma adaptação do processo apresentado por Mark Kasunic [Kasunic 2005], contendo cinco etapas: Planejamento, Elaboração, Teste Piloto, Execução e Análise.

$\mathrm{Na}$ etapa de Planejamento, definiu-se o objetivo da pesquisa: identificar e dar visibilidade às ações dos projetos parceiros; seu público-alvo: projetos parceiros do Programa Meninas Digitais localizados na região Sul do Brasil; a amostra: todos os projetos; e o tipo de instrumento: questionário online.

$\mathrm{Na}$ etapa de Elaboração, as questões foram definidas e o instrumento construído. O questionário completo ${ }^{1}$ contém 42 questões divididas nas seguintes seções: termo de consentimento livre e esclarecido, dados gerais, ações de extensão, ações de ensino, ações de pesquisa, ações de gestão, ações no período pandêmico e informações adicionais. $\mathrm{O}$ termo de consentimento livre e esclarecido apresenta o objetivo da pesquisa, seus riscos e benefícios, e solicita a anuência da coordenação do projeto. A fim de reduzir o tempo de resposta e minimizar o cansaço da(o) participante, questões fechadas foram utilizadas sempre que possível e a opção "Outro" foi incluída para permitir a inserção de respostas personalizadas.

\footnotetext{
${ }^{1}$ Link para o questionário:

https://drive.google.com/file/d/1cxcOammZUJNpFzTqVYwlsLo2CIEkWuZC/view?usp=sharing
} 
Em janeiro de 2021, um teste piloto foi realizado com um dos projetos parceiros a fim de identificar questões e opções de respostas com problemas (validade de constructo) e corrigi-las.

Na etapa de Execução, o questionário foi enviado para a coordenação dos projetos e as respostas foram coletadas no período de janeiro a março de 2021. Inicialmente, a página do Programa Meninas Digitais [SBC 2021] foi consultada para obter os títulos dos projetos e o contato de sua respectiva coordenação. Entretanto, como apenas um projeto respondeu ao questionário, foi necessário uma busca em redes sociais, nas páginas dos projetos, em reportagens ou mesmo em artigos científicos, a fim de obter o contato atualizado da coordenação.

$\mathrm{Na}$ etapa de Análise, as respostas abertas foram analisadas utilizando a técnica de Análise de Conteúdo [Moraes 1999], em que as respostas foram lidas e as informações principais extraídas, gerando um ou mais códigos por resposta. Então, os códigos com ideias semelhantes foram agrupados, gerando categorias e a frequência em cada categoria foi registrada. Por fim, os resultados (das respostas abertas e fechadas) foram descritos e interpretados.

\section{Resultados e Discussões}

Todos os 23 projetos parceiros da região Sul do Brasil participaram da pesquisa, portanto esta pesquisa possui nível de confiança igual a 100\% e não possui erro amostral. Entretanto, segundo suas coordenações, três projetos não estão ativos: "B-LABS Girls", "CTRL + Gurias" e "Bit Rosa - Elas na Computação". Dessa forma, o Quadro 1 apresenta os dados dos 20 projetos ativos.

Quadro 1. Dados dos projetos ativos participantes da pesquisa

\begin{tabular}{|c|c|c|c|c|c|c|c|c|}
\hline & & & & \multicolumn{4}{|c|}{ Ações } & \\
\hline Est & Id & Projeto & Instituição & EX & PE & EN & GE & Abrang \\
\hline \multirow{7}{*}{$\mathrm{RS}$} & 1 & $\begin{array}{l}\text { Desenvolvimento do Raciocínio } \\
\text { Lógico no Ensino Fundamental e } \\
\text { Médio }\end{array}$ & FURG & $\mathrm{x}$ & $x$ & - & - & Regional \\
\hline & 2 & $\begin{array}{l}\text { ENIGMA Mulheres na } \\
\text { Computação }\end{array}$ & UFRGS & $\mathrm{X}$ & $x$ & $x$ & - & Nacional \\
\hline & 3 & Gurias Digitais & URI & $x$ & - & - & - & Local \\
\hline & 4 & Gurias na Computação & UNIPAMPA & $\mathrm{X}$ & $\mathrm{x}$ & $\mathrm{X}$ & $x$ & Nacional \\
\hline & 5 & \#Include < Gurias> & UERGS & $\mathrm{x}$ & $\mathrm{x}$ & $\mathrm{X}$ & $\mathrm{x}$ & Nacional \\
\hline & 6 & Meninas Digitais na Computação & UNIJUI & $\mathrm{x}$ & - & $\mathrm{X}$ & - & Local \\
\hline & 7 & Meninas Digitais na IENH & IENH & $\mathrm{X}$ & - & $\mathrm{x}$ & - & Regional \\
\hline
\end{tabular}




\begin{tabular}{|c|c|c|c|c|c|c|c|c|}
\hline & 8 & Meninas Digitais Tchê Missões & URI & $x$ & $x$ & $x$ & - & Regional \\
\hline & 9 & Meninas High-tech & IFRS & $x$ & $\mathrm{x}$ & $x$ & - & Local \\
\hline \multirow{5}{*}{$\mathrm{SC}$} & 10 & Catarinas & UDESC & $x$ & $\mathrm{x}$ & $x$ & $\mathrm{x}$ & Nacional \\
\hline & 11 & Elas Digitais & IFSC & $x$ & $\mathrm{x}$ & - & - & Regional \\
\hline & 12 & JoinGirls & UNIVILLE & $x$ & - & $x$ & $\mathrm{X}$ & Regional \\
\hline & 13 & Meninas Digitais - UFSC & UFSC & $x$ & $\mathrm{x}$ & - & $x$ & Regional \\
\hline & 14 & Meninas Digitais Vale do Itajaí & FURB & $x$ & $\mathrm{x}$ & - & - & Regional \\
\hline \multirow{6}{*}{ PR } & 15 & Code and Ladies & UTFPR & $x$ & $x$ & - & - & Regional \\
\hline & 16 & Conectadas & UEM & $x$ & $\mathrm{X}$ & - & - & Local \\
\hline & 17 & Emili@s: Armação em Bits & UTFPR & $x$ & - & $x$ & $\mathrm{x}$ & Estadual \\
\hline & 18 & Link com Elas & UniCesumar & $x$ & $x$ & $x$ & - & Nacional \\
\hline & 19 & Manna Team & $\begin{array}{l}\text { UEM, UFPR, } \\
\text { IFPR, UTFPR, } \\
\text { UFMG, UFV, } \\
\text { IFSP }\end{array}$ & $x$ & $x$ & $\mathrm{x}$ & $\mathrm{x}$ & Estadual \\
\hline & 20 & TIChers & UTFPR & $X$ & $x$ & - & - & Local \\
\hline
\end{tabular}

Est $=$ Estado, $\mathrm{Id}=$ Identificador, $\mathrm{EX}=$ Extensão, $\mathrm{PE}=$ Pesquisa, $\mathrm{EN}=$ Ensino, $\mathrm{GE}=$ Gestão, Abrang= Abrangência.

Dos 20 projetos ativos, nove estão localizados no Rio Grande do Sul, cinco em Santa Catarina e seis no Paraná. A grande maioria dos projetos (17) possui sede em cidades do interior. Entre todos os projetos, 13 estão registrados em suas instituições na modalidade extensão, três na modalidade pesquisa, um como projeto de ensino e três não estão formalmente registrados. Todos os projetos desenvolvem ações de extensão (EX), 15 projetos realizam ações de pesquisa (PE), 12 projetos realizam ações de ensino (EN) e sete projetos realizam ações de gestão (GE).

Esses números na extensão justificam-se pelo alinhamento da maioria das ações com o objetivo do Programa Meninas Digitais, que induz o desenvolvimento de ações junto aos anos finais do ensino fundamental e ensino médio. Entretanto, a discussão de gênero na Computação vai bastante além da divulgação da área na educação básica. Envolve problematizar questões estruturais (ex.: preconceito, estereótipos de gênero, 
representatividade, assunção de papéis de liderança), que têm impacto na permanência de mulheres nos cursos de graduação e pós-graduação.

Todos os projetos ativos são vinculados a Universidades, em que se observa altos índices de evasão, portanto é compreensível que ações de ensino sejam realizadas com objetivo de estimular a permanência de mulheres nos cursos de graduação e pósgraduação. Ainda, alguns projetos realizam ações de gestão, como a conscientização do corpo docente, o enfrentamento da evasão e da retenção; e acompanhamento de egressas e egressos.

No trabalho de Maciel e Bim (2016) são destacados alguns projetos parceiros, bem como ações desenvolvidas em eventos científicos. Eles percebem o surgimento de diversos financiamentos de órgãos de fomento para pesquisas na área de inclusão de mulheres na Computação, o que estimulou muitos docentes a realizarem ações de pesquisa. Além disso, o surgimento de eventos científicos com objetivo de divulgar ações voltadas a mulheres na área da Computação, justifica o envolvimento de muitos projetos na realização de pesquisas.

Ainda, a grande maioria dos projetos (16) realizaram ações durante o período pandêmico. Em relação à abrangência, cinco projetos possuem abrangência nacional, dois estadual, oito regional e cinco local. O projeto Gurias na Computação informou que, embora promova algumas ações com abrangência nacional, a maioria das ações promovidas possui abrangência local.

Para além dos objetivos do Programa Meninas Digitais, 15 projetos indicaram outros objetivos que foram agrupados, conforme apresentado no eixo vertical do gráfico mostrado na Figura 1.

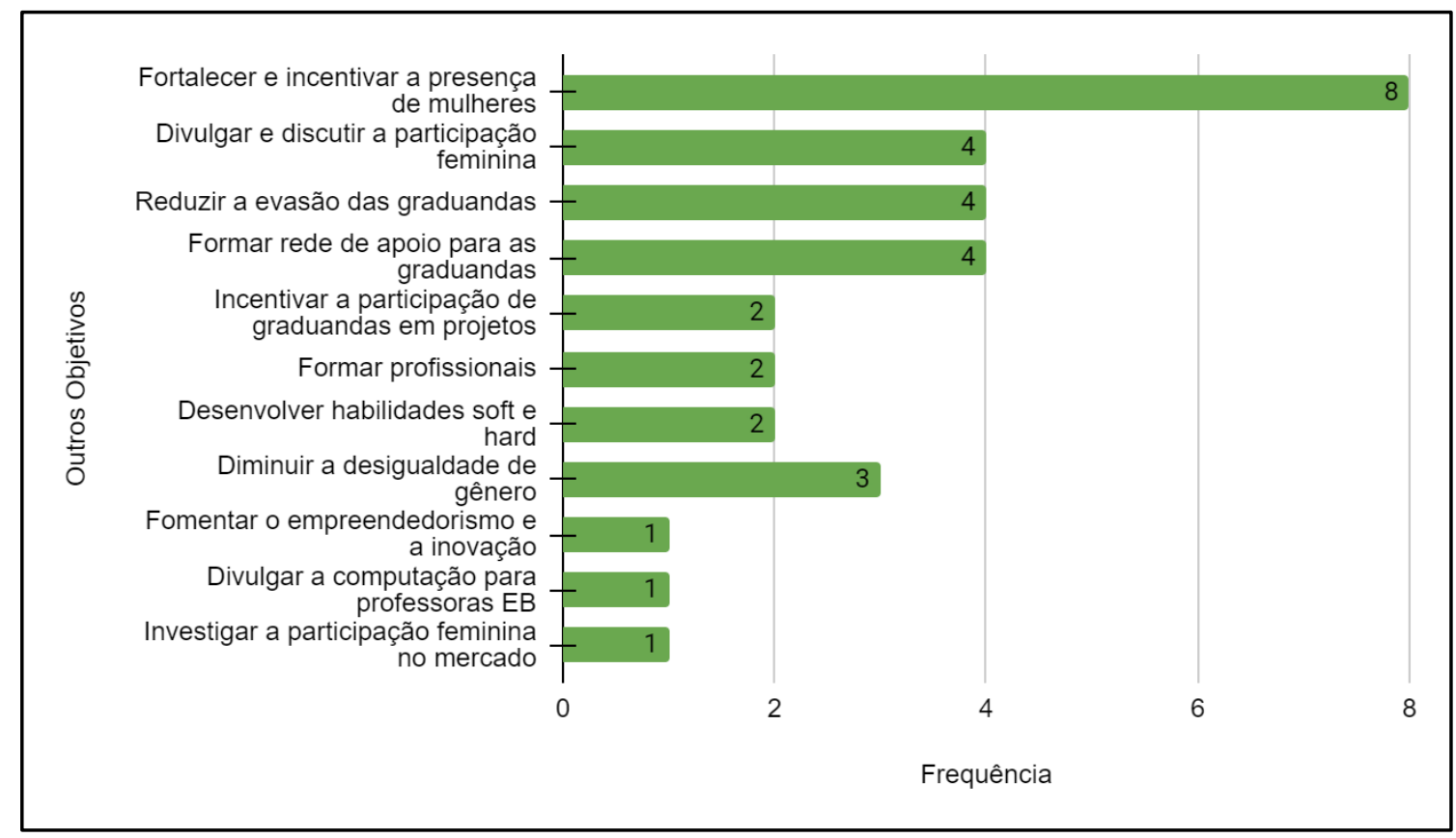

Figura 1. Outros objetivos dos projetos parceiros

Alguns desses objetivos estão relacionados ao ambiente universitário em que estão inseridos, como reduzir a evasão e fomentar a participação de graduandas em projetos. Já outros objetivos são mais gerais e podem ser trabalhados junto a diferentes 
públicos, como o intuito de fortalecer e incentivar a presença de mulheres na área, que podem ser explorados tanto com as estudantes da educação básica, como com as graduandas, as egressas, as profissionais no mercado de trabalho, entre outros.

A maioria dos projetos parceiros (18) inclui em seu público-alvo as meninas estudantes do ensino médio e dos anos finais do ensino fundamental, portanto estão mais alinhados ao objetivo do Programa Meninas Digitais. As exceções são os projetos TIChers e Link com Elas, que possuem como público-alvo as professoras da educação básica e as discentes dos cursos de graduação nas áreas de TI da educação a distância, respectivamente.

Além do projeto Link com Elas, outros 16 projetos possuem entre seu públicoalvo as mulheres estudantes dos cursos de graduação de Computação. Já as mulheres estudantes dos cursos de pós-graduação de Computação são alvo de 11 projetos, as egressas de 13 projetos e um projeto inclui as mulheres em empresas de software. Ainda, dois projetos têm entre seu público-alvo as meninas estudantes da educação infantil e sete projetos incluem ações para as meninas estudantes dos anos iniciais do ensino fundamental. Em relação à rede de ensino, 12 projetos buscam atingir as redes de ensino pública e privada, sete projetos somente a rede de ensino pública, um projeto somente a rede de ensino privada e um projeto respondeu "não se aplica".

Com o objetivo de conhecer as temáticas mais trabalhadas, foi questionado quais as temáticas que cada projeto abordava nas ações de extensão (EX), pesquisa (PE) e ensino (EN). O gráfico, apresentado na Figura 2, mostra o quantitativo de projetos que trabalham ou já trabalharam com cada uma dessas temáticas.

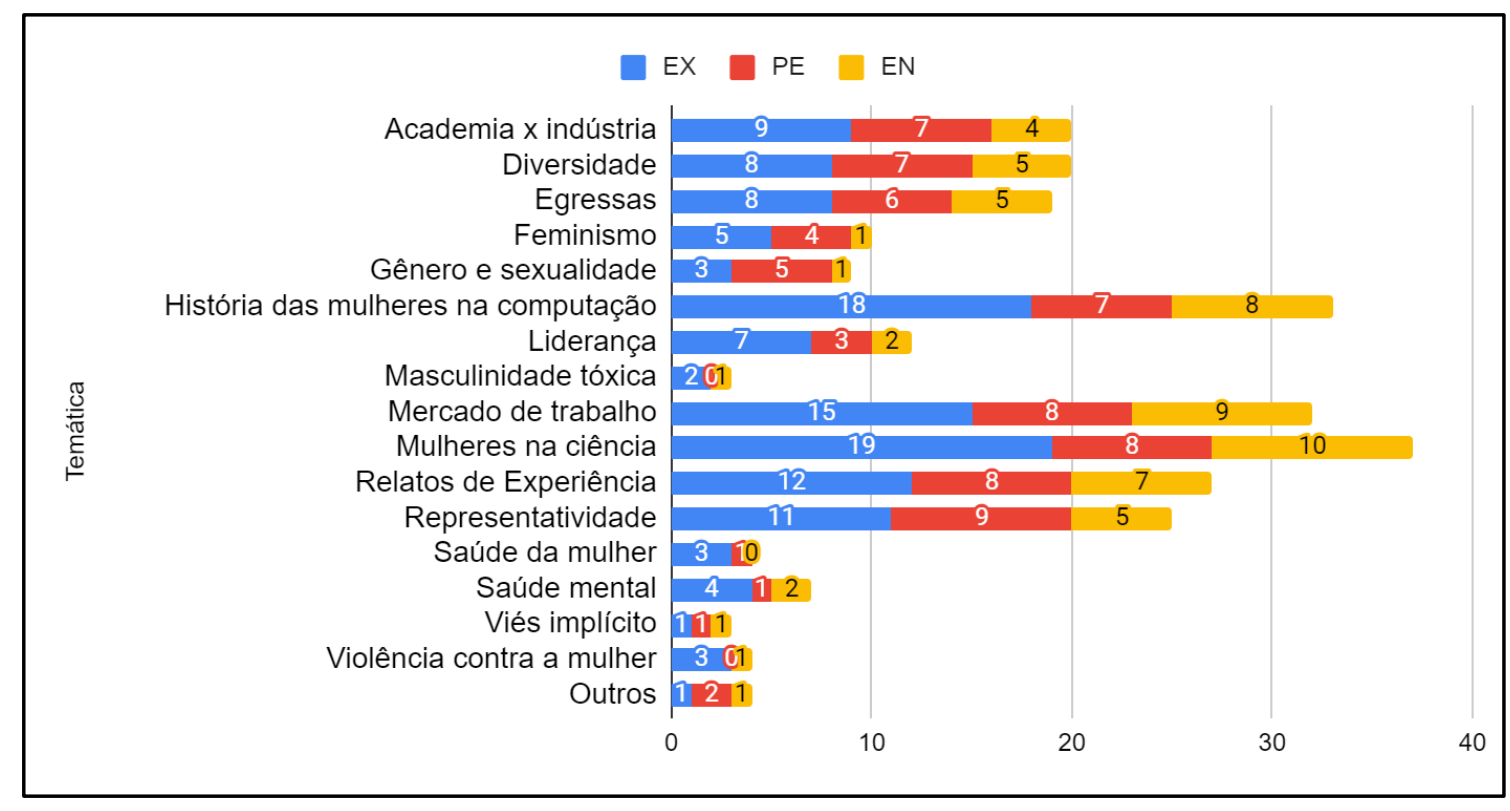

Figura 2. Temáticas das ações de Extensão, Pesquisa e Ensino

Entre as temáticas mais abordadas pelos projetos parceiros estão: Mulheres na Ciência, História das Mulheres na Computação, Mercado de Trabalho, Relatos de Experiência e Representatividade. Esses dados mostram que há um espaço aberto para parceria entre os projetos, inclusive com a possibilidade de eventos regionais.

Por outro lado, esse gráfico também expõe temáticas ainda pouco trabalhadas nos projetos parceiros: Gênero e Sexualidade, Masculinidade Tóxica, Saúde da Mulher, Viés 
Implícito e Violência contra a Mulher. Essas temáticas englobam questões importantes de serem discutidas no ambiente acadêmico, no sentido de não só proporcionar um acolhimento para as mulheres cis-gênero, mas também mulheres trans-gênero ou pessoas não binárias. Algumas respostas ao questionário, inclusive, mostraram que ainda existe bastante confusão com relação aos significados desses termos.

Com o objetivo de salientar as temáticas trabalhadas em cada projeto, foram elaborados gráficos separados para as ações de extensão (Figura 3), pesquisa (Figura 4) e ensino (Figura 5), onde, em cada um, os projetos estão numerados (conforme Quadro 1) no eixo horizontal e as temáticas apresentadas no eixo vertical. A célula pintada representa que o projeto trabalha ou trabalhou com aquela temática.

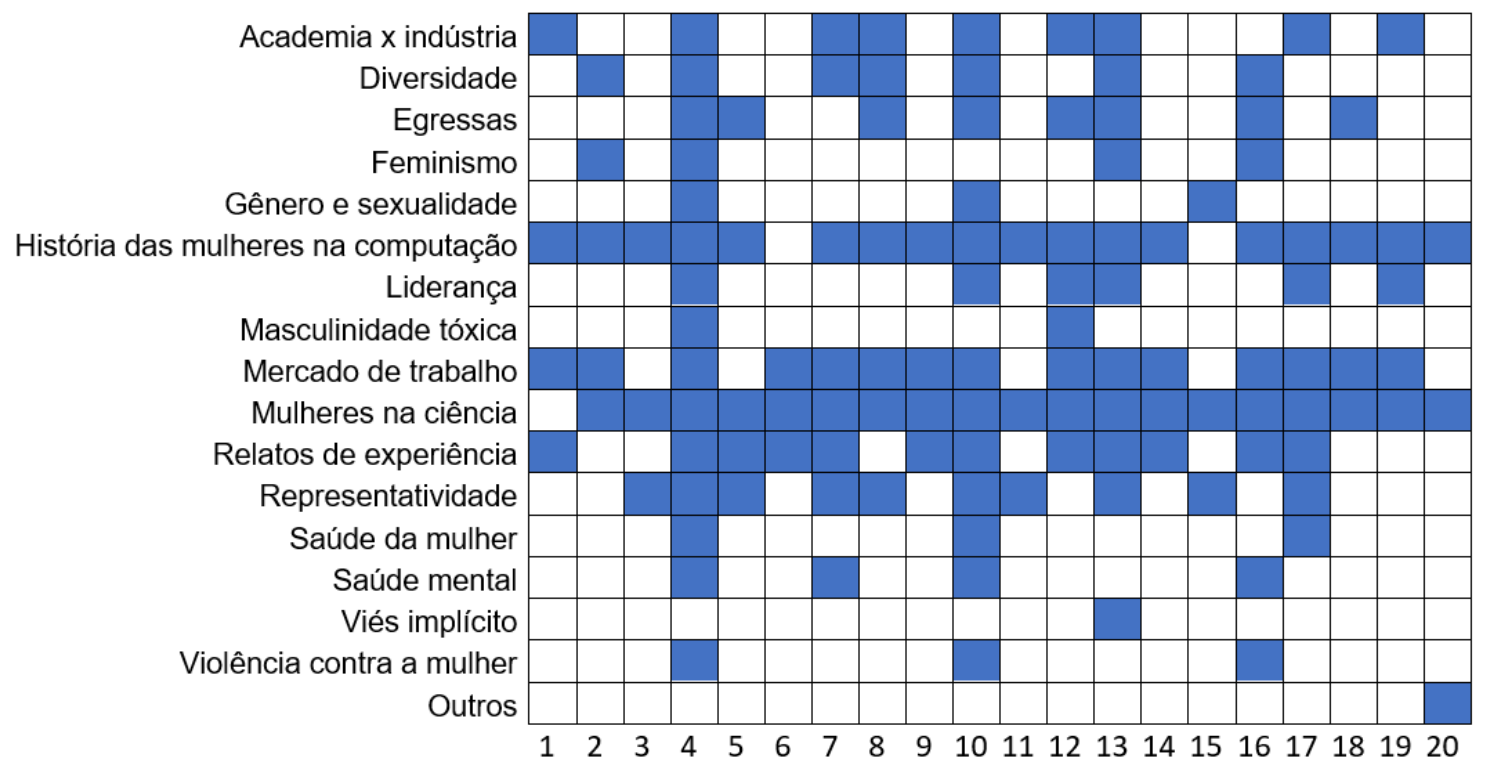

Figura 3. Temáticas das ações de Extensão

Observa-se, na Figura 3, que as temáticas mais trabalhadas na extensão são Mulheres na Ciência, História das Mulheres na Computação e Mercado de Trabalho. Essas temáticas dialogam com os objetivos do Programa Meninas Digitais, porque visam apresentar a Computação como uma possibilidade para as meninas e, assim, atraí-las para os cursos da área.

Destaca-se que os projetos Gurias na Computação (4), Catarinas (10) e Meninas Digitais - UFSC (13) possuem temáticas similares, assim como os projetos ENIGMA: Mulheres na Computação (2) e Conectadas (16). Na temática Violência Contra a Mulher, os projetos Gurias na Computação (4), Catarinas (10) e Conectadas (16) são referências. Já na temática Feminismo, os projetos ENIGMA: Mulheres na Computação (2), Gurias na Computação (4), Conectadas (16) e Link com Elas (18) possuem ações. O projeto TIChers (20) realiza ações de extensão em que diferentes assuntos da área da Computação são abordados (Outros).

A partir da Figura 4 é possível perceber que as temáticas representatividade, Mercado de Trabalho, Mulheres na Ciência e Relatos de Experiência são as mais trabalhadas em ações de pesquisa entre os projetos. Infere-se que a investigação dessas temáticas visa mapear a participação feminina na área da Computação e contribuir para ampliar o número de mulheres tanto nos cursos de Computação quanto no mercado de trabalho de TI pela indução de políticas e projetos institucionais. 


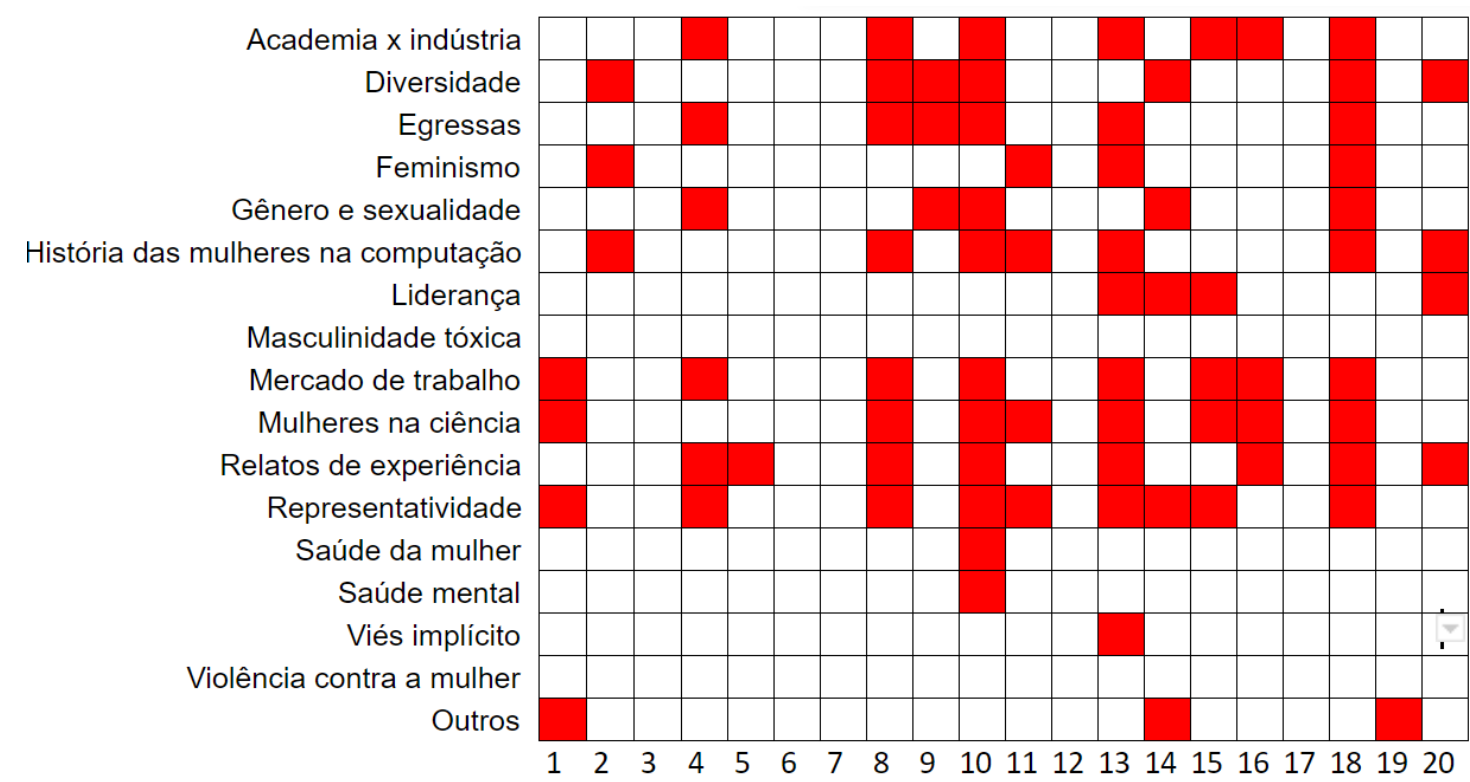

Figura 4. Temáticas das ações de Pesquisa

Destaca-se que os projetos Meninas Digitais Tchê Missões (8), Catarinas (10) e Link com Elas (18), por exemplo, apresentam mais de uma temática em comum. Salientase, ainda, que outras temáticas são mencionadas: Pensamento Computacional, e Neurociência, trazidas pelo projeto Desenvolvimento do Raciocínio Lógico no Ensino Fundamental e Médio (1); Jogos, citada pelo projeto Meninas Digitais Vale do Itajaí (14); e Pensamento Computacional, Internet das Coisas, Internet dos Drones, Felicidade e Educação 5.0, abordadas pelo projeto Manna Team (19).

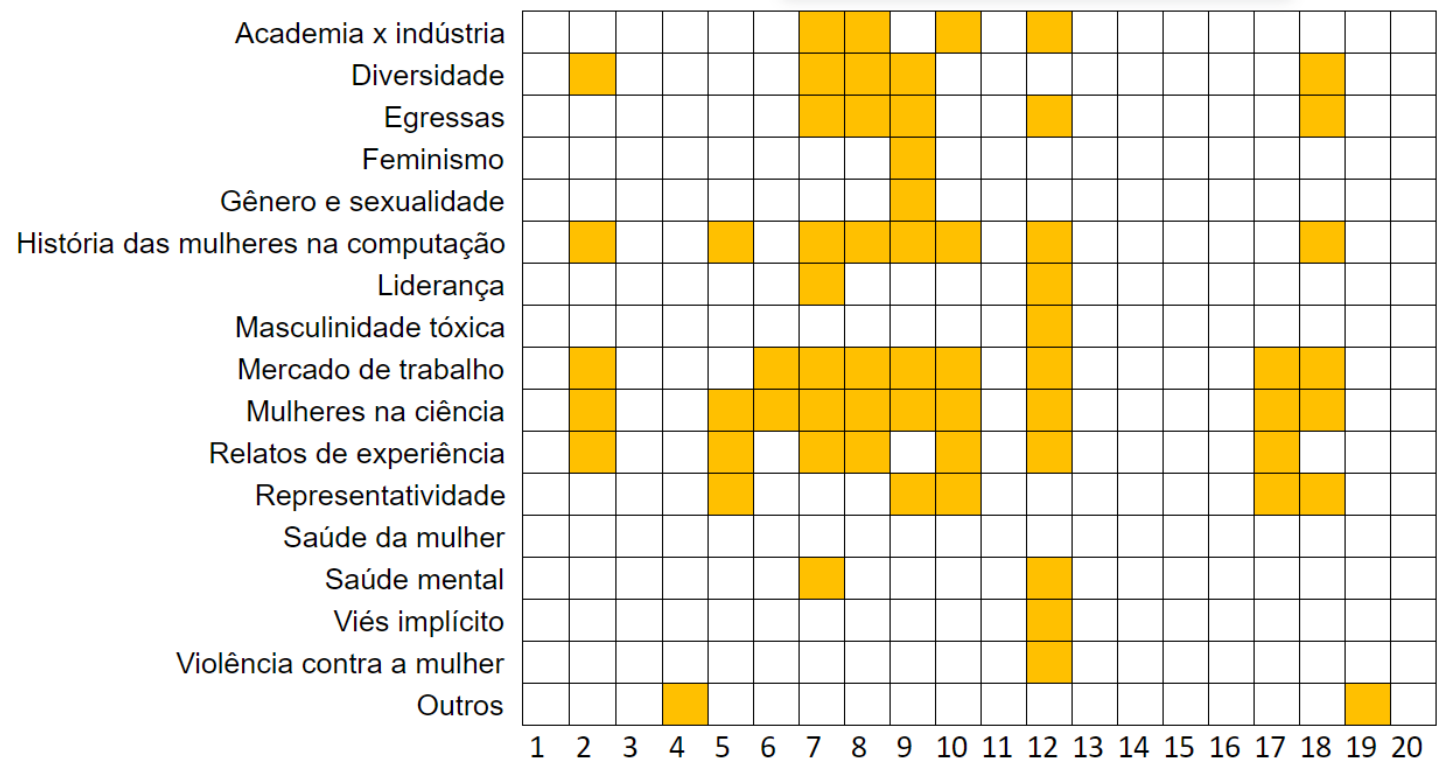

Figura 5. Temáticas das ações de Ensino

As temáticas mais trabalhadas nas ações de ensino são as mesmas das ações de extensão: Mulheres na Ciência, História das Mulheres na Computação e Mercado de Trabalho. Entende-se que os materiais produzidos para as ações de extensão se apliquem também às ações de ensino, que podem ter como objetivo reduzir os índices de evasão nos cursos de graduação. Nas ações de ensino, os projetos Meninas Digitais na IENH (7), 
Meninas Digitais Tchê Missões (8) e JoinGirls (12) trabalham temáticas similares, assim como os projetos ENIGMA: Mulheres na Computação (2) e Link com Elas (18). Ainda, o projeto Gurias na Computação indicou trabalhar no fortalecimento da relação entre professoras e graduandas e o projeto Manna Team indicou abordar as temáticas Felicidade e Inovação (Outros).

Conforme pode ser observado nas Figuras 3, 4 e 5, os projetos parceiros, além de trabalharem temas de interesse à divulgação da Computação a estudantes das séries finais do ensino fundamental e do ensino médio, abordam muitas outras temáticas. Para isso, adotam diferentes estratégias, sendo as mais frequentes na extensão: oficinas, encontros e palestras; na pesquisa: artigos, pôsteres e resumos; e no ensino: oficinas e minicursos.

\section{Considerações Finais}

A maioria dos projetos parceiros estão alinhados com os objetivos do Programa Meninas Digitais. Contudo, seus objetivos também alcançam outros públicos, como estudantes de graduação e de pós-graduação em Computação, egressas de cursos de Computação e mulheres em empresas de software, meninas da educação infantil e dos anos iniciais do ensino fundamental. Isso é um indicativo da complexidade envolvida na abordagem da inclusão da mulher na área da Computação, que vai muito além de divulgar a área, mas também envolve abordar temas sensíveis para a permanência das mulheres na área.

Os resultados encontrados evidenciam temas que têm sido investigados e abordados pelos projetos parceiros da região Sul do Brasil. Propõe-se a cooperação entre esses projetos pelo compartilhamento de materiais ou pela realização de ações online em conjunto (ex.: cursos, oficinas, eventos técnico-científicos, ciclos de palestras, rodas de conversa, entre outros).

Considerando-se as dificuldades em obter informações atualizadas sobre os projetos, recomenda-se atualização sistemática da página do Programa Meninas Digitais. Ademais, destaca-se a importância de manter atualizadas as informações relevantes como a coordenação de cada projeto, o contato de e-mail do projeto, bem como da pessoa responsável pela coordenação, uma vez que alguns e-mails de projetos não foram retornados.

Entre as limitações desta pesquisa, observam-se: $(i)$ somente projetos divulgados no site do Meninas Digitais foram incluídos na amostra; (ii) o fato de o questionário dividir as ações nas modalidades extensão, pesquisa, ensino e gestão pode ter dificultado a participação de projetos não vinculados a instituições de ensino superior; (iii) o instrumento não permite identificar se houve ou há cooperação entre os projetos; e (iv) o instrumento também não identifica os cursos de graduação ou pós-graduação aos quais os projetos são vinculados.

Como trabalhos futuros, sugerem-se: (i) aplicar esta pesquisa em outras regiões do Brasil; (ii) investigar se os temas de pesquisa indicados pelos projetos parceiros da região Sul do Brasil refletem em suas publicações no WIT; e (iii) articular ações envolvendo os projetos.

\section{Agradecimentos}

À Pró-reitoria de Extensão e Cultura da Unipampa. Ao Programa de Desenvolvimento Educacional da Unipampa. À toda a comunidade envolvida com as ações mencionadas. 


\section{Referências}

Frigo, L. B.; Moro, F. F.; Padilha, R. O.; Pozzebon, E. (2020). Meninas em Ação: Atividades Inspiradoras para Projetos Parceiros do Programa Meninas Digitais. In Anais do XIV Women in Information Technology, p. 60-69, Porto Alegre, RS, Brasil. SBC.

Kasunic, M. (2005). Designing an effective survey. Technical Report. DTIC Document.

Maciel, C.; Bim, S. A. (2016). Programa Meninas Digitais - ações para divulgar a Computação para meninas do ensino médio. In Anais do Computer On the Beach 2016, p. 327-336.

Moraes, R. (1999). Análise de Conteúdo. Revista Educação, Porto Alegre, 22, 37, p. 7 32.

Nunes, M. A. S. N.; Louzada, C; Salgueiro, E; Andrade, B.; Lima, P.; Monteiro, R. (2016a). Mapeamento de iniciativas brasileiras que fomentam a entrada de mulheres na Computação. In Anais do X Women in Information Technology, p. 2692-2696.

Nunes, M. A. S. N., Louzada, C. S., Salgueiro, E.; Andrade, B.; Lima, P.; Monteiro, R. (2016b). Mapeamento de iniciativas estrangeiras que fomentam a entrada de mulheres na Computação. In Anais do X Women in Information Technology, p. 2697-2701.

SBC (2021). Programa Meninas Digitais. Disponível em: http://meninas.sbc.org.br/ Acesso em: 12 Mar. 2021. 